\title{
The Location of Industry
}

$\mathrm{T}$ HE attention which is now being given to the location of industry was reflected not only in Prof. P. Sargant Florence's presidential address to Section F (Economic Science and Statistics) of the British Association on September 3, but also in the discussion by the same Section on September 2 of problems of labour transference. Mr. H. C. Emmerson, assistant secretary to the Ministry of Labour, who opened the discussion in place of Mr. Humbert Wolfe, described the work which the Ministry of Labour has been carrying out since 1928 to assist the unemployed. Men and women from the depressed areas are given the first opportunity of vacancies in other areas and are assisted if necessary by free travel, special allowances and a lodging allowance. In 1936, no fewer than 20,000 men and 8,000 women were placed through the exchanges. A juvenile employ. ment scheme was started in 1928, and Mr. Emmerson also described a household removal scheme by which a man is assisted to take his family to the place of his new employment, and a family removal scheme which sends members of one family to work in one place. 10,000 removals have taken place under the two schemes.

The Ministry of Labour's present policy is largely directed to the movement of workers to specific vacancies, and this was severely criticized by Mr. S. R. Dennison, of the University of Manchester, who argued that in spite of the success achieved the basic policy is sometimes wrong. Employers expect a higher standard of work from men supplied by the exchanges than from those recruited directly. Mr. Dennison believes that transference should be accelerated not during boom years but when there is a slump, and urged that the Ministry should be filling 90 per cent of the vacancies instead of the present 25 per cent. In Lancashire, the existence of a family income is a strong deterrent, and $\mathrm{Mr}$. Dennison also considers that with the present policy a depressed area is left heavily weighted with unem. ployed in the lower and higher age groups, and in consequence with more dependants, a falling income and increased depression. In that direction complete evacuation is the only logical policy.

The social consequences of industrial transference were discussed in a paper by Mr. A. D. K. Owen. For communities from which transference has taken place on an appreciable scale, the most obvious consequence is either a diminution in population growth or an actual fall in population. Up to the present, the high rate of natural increase (due to relatively low death-rate and high birth-rate) in the areas from which most transference has taken place has compensated to some extent for the loss of population by migration. More important, however, are the modifications in the age-structure of the population resulting from migration. Industrial transferees are mostly young people; there has in consequence been a marked ageing of the population in the depressed areas, and this tendency will increase in the next few years. Moreover, as the transference is voluntary, it acts as a selective process which tends to lower the average quality of the population left behind. With some important exceptions, it is the more active and adventurous elements in the community which tend to migrate. The immediate effect of transference is to reduce unemployment in the depressed areas from which it takes place, but the ultimate effect may well be different, especially if skilled or potentially skilled workers are transferred. Denudation of skilled workers or of the most promising young workers may actually increase unemployment by impeding the development of new industries and in time depressing existing industries still further. The development of new industries in the depressed areas has already involved the return of some skilled transferees.

Where transference has resulted in an appreciable fall in population, it has considerably eased the problem of overcrowding as well as reduced the pressure on local social services, but there are losses in institutional life as well as in rate income. For communities to which transference has taken place there is a valuable gain in population, which provides a basis for industrial expansion but also raises many difficult problems for local government authorities in the expanding areas. Overcrowding is very serious, as well as transport problems and the provision of a sufficient number of new schools. In spite of difficulties of assimilation and social friction, the introduction of large numbers of new workers and their families into fresh areas is socially in. vigorating, and the redistribution of the labour supply in relation to economic opportunities represents a considerable economic gain. On the other hand, there is some reason to believe that subsidized transference is artificially distorting the industrial structure of the country. For the community as a whole the greatest gain from industrial transference has been the salvaging of young workers from the deteriorating effect of long-continued unemployment, and this must be set against the waste of social capital in the areas from which transference takes place and the devitalization of provincial or even national culture. Mr. Owen considered industrial transference should continue along different lines related to a broad plan of national development which takes account of both economic and social factors.

Dr. O. A. Oesser, in a paper on psychological and sociological aspects of labour transference, first reviewed the problems involved in relation to the condition of the material available for transfer. Highly skilled workers are more easily transferred, provided jobs are available for which their training is adequate, not only because transfer from a more skilled to a less skilled job is easier than the reverse, but also because of their frequent tradition of emigration and their higher intelligence level, wider knowledge, training and flexibility. The type of educational system may also be a factor. The social and economic conditions of the areas between which transfer is to be made must next be considered. People can be moved from areas of lower to areas of higher standards of living, but local patriotism and reluctance to move may be obstacles, as well as traditions and a sub. jective social status of occupation. Finally, Dr. Oesser suggested that the condition and state of industries in the area must be considered in relation to those of Great Britain as a whole, and he used the jute industry as an example to illustrate the growth of new social patterns among the unemployed and the mobility of labour between occupations. 